\title{
LETTER
}

\section{The Human Reelin Gene: Isolation, Sequencing, and Mapping on Chromosome 7}

\author{
Udaya DeSilva, ${ }^{1}$ Gabriella D'Arcangelo, ${ }^{2}$ Valerie V. Braden, ${ }^{1}$ June Chen, ${ }^{2}$ \\ Graham G. Miao, ${ }^{2}$ Tom Curran, ${ }^{2}$ and Eric D. Green ${ }^{1,3}$
}
${ }^{1}$ Genome Technology Branch, National Center for Human Genome Research, National Institutes of Health, Bethesda, Maryland 20892; ${ }^{2}$ Department of Developmental Neurobiology, St. Jude Children's Research
Hospital, Memphis, Tennessee 38105

\begin{abstract}
The mouse reelin gene $(R e / n)$ encodes a novel protein that, when mutated, results in the characteristic reeler phenotype. A key component of this phenotype is the extensive disruption of the organization of many brain structures. Reelin is believed to be an extracellular protein that controls neural cell positioning during brain development. The reelin gene is conserved in many vertebrate species, including humans. To study the role of the reelin homolog in human brain development, we have isolated and characterized the human gene (RELN). Like its murine counterpart, RELN is large, encoding an mRNA of $\sim 12 \mathrm{~kb}$. Overlapping CDNA clones containing the entire open reading frame were isolated and sequenced, revealing that the predicted mouse and human proteins are similar in size ( $388 \mathrm{kD}$ ) and that the amino acid and nucleotide sequences are $94.2 \%$ and $87.2 \%$ identical, respectively. Northern hybridization analyses revealed that RELN is expressed in fetal and postnatal brain as well as liver. The expression of RELN in postnatal human brain was high in the cerebellum. RELN was mapped to human chromosome 7q22, based on both fluorescence in situ hybridization studies and localization within a well-positioned yeast artificial chromosome (YAC) contig. The YAC contig also contains a number of genetic markers. Together, these studies provide the sequence information and genetic tools for performing more detailed analyses of RELN in an attempt to define its role in human brain development and possibly in human disease.
\end{abstract}

[The sequence data described in this paper have been submitted to GenBank under accession no. U79716.]

The mouse autosomal recessive mutation, reeler, is associated with a characteristic phenotype, which includes both pronounced neurological symptoms (e.g., dystonia, ataxia, tremors) and striking abnormalities in the architecture of the telencephalic and cerebellar cortices (for review, see Caviness and Rakic 1978; Goffinet 1984, 1990, 1992). The defect in reeler mice has been known for many years to perturb the migration of postmitotic neurons during formation of the normal multilayered (laminar) structures in the cerebral cortex, cerebellum, hippocampus, and several other subcortical regions. As a result, the reeler mouse has provided a useful model for abnormal corticogenesis.

The gene responsible for the reeler mutation, Reln, was identified recently (D'Arcangelo et al. 1995). Three different reeler alleles $\left(\operatorname{Reln}^{r l}, \operatorname{Reln}^{\text {orl }}\right.$, and $\operatorname{Re}^{\mathrm{tg}}{ }^{\mathrm{g}}$ ) have been defined at a molecular level (D'Arcangelo et al. 1995; Takahara et al. 1996). Each

${ }^{3}$ Corresponding author.

E-MAIL egreen@nchgr.nih.gov; FAX (301) 402-4735. contains a partial deletion of the Reln coding sequence. The encoded protein is large, consisting of 3461 amino acids [derived from an open reading frame (ORF) of 10,383 nucleotides] and containing a deduced molecular mass of $388 \mathrm{kD}$. The reelin protein appears to be a novel extracellular matrix molecule containing an amino-terminal region with homology to F-spondin (Klar et al. 1992), as well as eight consecutive repeats, each with two related subdomains separated by an epidermal growth factor (EGF)-like motif (D'Arcangelo et al. 1995). Based on its predicted structure and pattern of expression in the mouse, reelin has been proposed to function as a neuron-specific extracellular protein that controls neuronal migration in the developing brain and stabilizes the architecture of laminar structures. Such a role is supported by immunological studies in the developing mouse employing the monoclonal CR-50 antibody (Ogawa et al. 1995), which recognizes reelin (D'Arcangelo et al. 1997).

Comparative human-mouse genome mapping has identified a region of conserved synteny be- 


\section{DeSILVA ET AL.}

tween human chromosome $7 \mathrm{q}$ and mouse chromosome 5 containing Reln (O'Brien et al. 1993; Bar et al. 1994; DeBry and Seldin 1996). We sought to characterize the human homolog of Reln, both to compare the sequences of the human and mouse genes and to establish its precise location in the human genome. Such studies should provide the foundation for defining the role of reelin in the human brain. Here, we report the isolation of a set of overlapping RELN cDNA clones and elucidation of the full-length coding sequence. In addition, we have determined the expression pattern of RELN and its precise location on human chromosome $7 \mathrm{q} 22$.

\section{RESULTS}

\section{Conservation of the Reelin Gene in Vertebrates}

To determine the degree to which reelin is evolutionarily conserved, Southern hybridization analysis using genomic DNA from several vertebrate species was performed with a Reln cDNA probe (corresponding to nucleotides 3268-3613; GenBank accession no. U24703). Hybridizing DNA fragments were detected in all samples under moderate stringency conditions (Fig. 1), indicating that Relnrelated sequences are highly conserved among vertebrates. No hybridization was detected using insect or plant DNA (data not shown).

\section{Cloning and Sequencing of RELN}

The established sequence of Reln (D'Arcangelo et al.

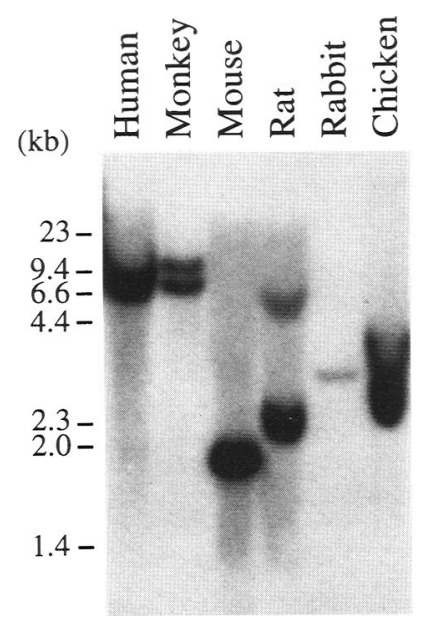

Figure 1 Evolutionary conservation of the reelin gene. EcoRI-digested genomic DNA from the indicated vertebrate species was subjected to gel-transfer hybridization with a ${ }^{32} \mathrm{P}$-labeled Reln CDNA probe. The relative positions of molecular mass markers are indicated (in kb).
1995) was used to design a series of PCR assays, a subset of which were found to amplify appropriately sized products from human DNA. The precise sequence of the resulting amplified products was established and used to design human-specific oligonucleotides, with the latter being used for "capturing" clones from a brain cDNA library (see Methods). Seven overlapping clones were isolated (these ranged in size from 2.2 to $4.8 \mathrm{~kb}$ and were ultimately found to account for $>90 \%$ of the coding sequence). Two additional cDNA clones were obtained by hybridization-based screening of a human cerebellum cDNA library using the insert ends of two previously isolated clones as probes. The resulting set of overlapping RELN cDNA clones is depicted in Figure 2.

A subset of the cDNA clones (indicated in Fig. 2) were mixed and sequenced by a shotgun strategy to establish the sequence of expressed RELN. The resulting sequence (GenBank accession no. U79716) revealed an ORF of 10,380 nucleotides, which begins at a conserved, consensus sequence for translation initiation that contains the initial methionine codon (GGCGGCAUGG) (Kozak 1991) and ends at an in-frame stop codon. The 5 '-untranslated region (UTR) contains a stretch of 10 repeated GGC triplets immediately proximal to the translation initiation site, whereas the 3 '-UTR contains a consensus polyadenylation signal. The nucleotide sequence of RELN is $87.2 \%$ identical to that of Reln. The coding regions exhibit $88.2 \%$ identity, whereas the $5^{\prime}$ and $3^{\prime}$ UTRs analyzed are $72.4 \%$ and $80.4 \%$ identical, respectively.

\section{Deduced Amino Acid Sequence of RELN}

RELN encompasses an ORF of 3460 amino acids that has a predicted molecular mass of $388 \mathrm{kD}$. The deduced human and mouse amino acid sequences are $94.2 \%$ identical, with the human protein being shorter by a single amino acid (Fig. 3). The amino terminus of both contains a signal peptide followed by a consensus cleavage site (von Heijne 1983, 1986). The signal peptide is less conserved between the human and mouse (66\% identical) than the rest of the protein. There are no other transmembrane domains. Similar to the mouse, the human reelin protein has an amino terminus with significant homology to F-spondin (Klar et al. 1992), whereas the rest of the protein consists of eight consecutive repeats of 350-390 amino acids, each containing two related subdomains separated by an EGF-like domain of 30 amino acids. These conserved repeats exhibit no similarity with other known proteins. 


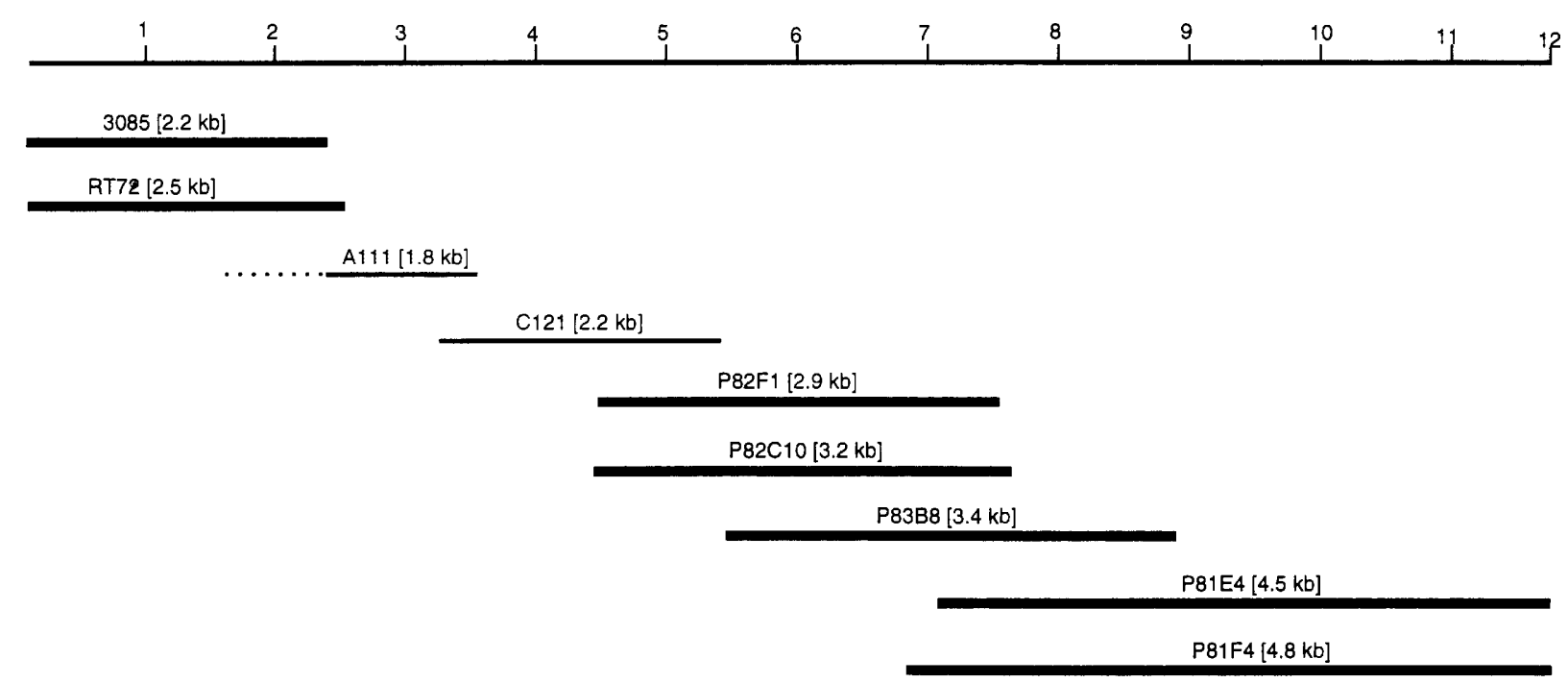

Figure 2 Contig map of RELN CDNA clones. The nine independent CDNA clones used to obtain the sequence of $R E L N$ are depicted. The seven clones indicated by thicker horizontal lines were isolated from a human brain CDNA library and used for shotgun sequencing. Clones C121 and A111 were isolated from a human cerebellum cDNA library, and the inserts of these clones were sequenced by successive walking with custom primers. The proximal end of clone A111 is chimeric (depicted as a dotted line).

\section{Tissue-Specific Expression of RELN}

Northern hybridization analyses revealed a tissuespecific pattern of expression for RELN. Hybridization of $R E L N$ cDNA probes to poly(A) RNA from various fetal and adult tissues revealed a transcript of $\sim 12 \mathrm{~kb}$ in fetal and adult brain as well as liver, but not in any other tissue examined (Fig. 4; data not shown). The expression pattern of $R E L N$ was examined in more detail in adult brain. A RELN transcript was detected in all brain regions examined, with the highest levels observed in the cerebellum (Fig. 4). The high level of postnatal expression of RELN in the cerebellum is reminiscent of that reported in the mouse (D'Arcangelo et al. 1995).

\section{Mapping RELN on Human Chromosome 7}

Three PCR assays specific for sequence-tagged sites (STSs) within the RELN cDNA sequence (sWSS2926, sWSS3174, and sWSS3176) were developed and verified to amplify the appropriate product from human genomic DNA. These STSs were scattered across RELN (corresponding to nucleotides 11141294, 10,525-10,685, and 11,314-11,551). All three STSs were localized on a single yeast artificial chromosome (YAC) contig that was constructed as part of a larger effort to assemble a physical map of human chromosome 7 (Green et al. 1991, 1994, 1995; G.G. Bouffard, J.R. Idol, V.V. Braden, L.M. Iyer, A.F. Cunningham, L.A. Weintraub, J.W. Touchman,
R.M. Mohr-Tidwell, D.C. Peluso, R.S. Fulton, et al., in prep.). The relevant portion of this YAC contig containing RELN is depicted in Figure 5. Although the exact size of the genomic interval containing RELN cannot be established based on the existing data, the smallest YAC containing all three RELNspecific STSs (yWSS2204) is $250 \mathrm{~kb}$. Importantly, the assignment of RELN to the contig shown in Figure 5 allows its placement on the human genetic map, because of the presence of eight genetic markers that lie in close physical proximity to the gene. A summary of these genetic markers is provided in Table 1. One gene [MSS1 (sWSS1845), GenBank accession no. D11094] and two ESTs (sWSS3569 and sWSS3871; GenBank accession nos. G30782 and G30871, respectively) map immediately centromeric to $R E L N$. Finally, RELN was found to map to band 7q22 based on fluorescence in situ hybridization (FISH) studies performed using YACs from the contig in Figure 5 as well as a P1 clone containing part of RELN (data not shown).

\section{DISCUSSION}

The study of mouse genetic mutations associated with profound phenotypes can provide valuable information about fundamental biological processes. Such insight can also be used to investigate the role of the corresponding genes in humans, both in healthy and disease states. In this paper, we have 
DeSILVA ET AL.

\begin{tabular}{|c|c|}
\hline 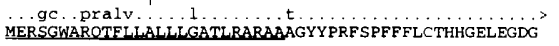 & 50 \\
\hline EQGEVLISLHIAGNPTYYVPGQEYWVTISTSTFFDGLLVTGLYTSTSVQA & 100 \\
\hline 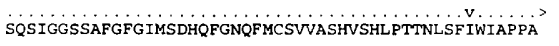 & 150 \\
\hline 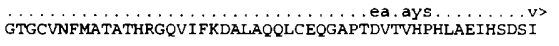 & 200 \\
\hline 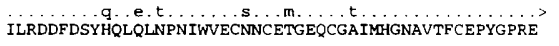 & 250 \\
\hline 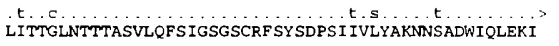 & 300 \\
\hline$\underset{\text { RAPSNVSTIIHILYLPEDAKGENVQFQWKQENLRVGEVYEACWALDNILI }}{\ldots}$ & 350 \\
\hline 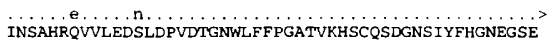 & 400 \\
\hline FNFATTRDVDLSTEDTQEQWSEEFESQPTGWDVLGAVIGTECGTIESGLS & 450 \\
\hline 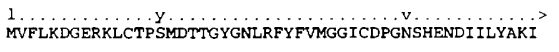 & 500 \\
\hline EGRKEHI TLDTLSYSSYKVSLVSVUINPELQTPATKFCLRQKNHQGHNR & 550 \\
\hline NWWAVDFHVLPVLPSTMSHMI PFSINLGCGTHQPGNSVSLEFSTNHGRS & 600 \\
\hline WSLLHTECLPETCAGPHLPHSTVYSSENYSGWNRITIPLPNAALTRNTRI & 650 \\
\hline RWRQTGPILGNMWAIDNVY IGPSCLXPCSGRGQCTRHGCKCDPGYSGPAC & 700 \\
\hline EMASQTFPMFISESFGSSRLSSYHNFYSIRGAEVSFGCGVLASGKALVFN & 750 \\
\hline 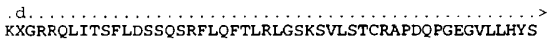 & 800 \\
\hline YDNG I TWKLLEHYSYLSYHEPRII SVELPGDAKQFGIQFRWWQPYHSSQR & 850 \\
\hline EDVWAIDEITMTSVLFNSISLDFTNLVEVTQSLGFYLGNVPYCGHDWTL & 900 \\
\hline CFTGDSKLASSMR YVETQSMQIGASYMIOF SLVMGCGEKYTPHMDNQVKL & 950 \\
\hline EYSTNHGLTWHLVQEECLPSMPSCEEFTSASTYHASEFTQWRRVYVLLPQ & 1000 \\
\hline KTWSSATRFRWSQSYYTAQDEWALDSTYIGQOCPMMCSOYGSCDHGICRC & 1050 \\
\hline DQQYQOTECHPEAALSTIMSDFENQNGWESWQEVTGGETVKEEQGGG & 1100 \\
\hline ISSGSSLYFSKAGKRQVSWDLDTSWVDFVQFYIQIGGESASCNKPDSRE & 1150 \\
\hline 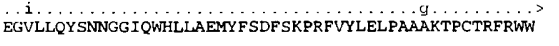 & 1200 \\
\hline QPVFSGEDYDQWAVDDIILSEKQKQIIPVINPTLPQNFYEKPAFDYMMN & 1250 \\
\hline QMSWWLMLANEGMVNETECCAATPSAMIFGKSDGDRFAVTRDLTLKPGY & 1300 \\
\hline 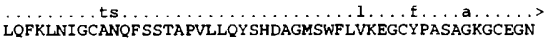 & 1350 \\
\hline SRELSEPTMYYTGDEEEWTRITIVI PRSLASSKTRRRWIQESSSQRNVPP & 1400 \\
\hline FGLDGVY I SEPCPSYCSGHODCISGUCPCDLAYTMRQGTCVSNVPNHNEM & 1450 \\
\hline FDRFEGKLSPLWYKITGAQVGTGCGTLNDGKSLYFNGPGKREARTVPLDT & 1500 \\
\hline 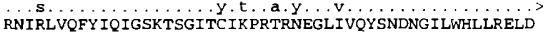 & 1550 \\
\hline FMSLLEPQI ISIDLPQDAKTPATAFRWWQPQHGKHSAQWALDDULIGMND & 1600 \\
\hline SSQTGFQDKFDGSIDLQANWYRIOGGQVDIDCLSMDTALIFTENIGKPRY & 1650 \\
\hline 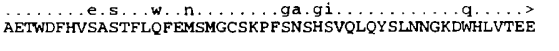 & 1700 \\
\hline 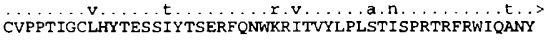 & 1750 \\
\hline TVGADSWA IDNVVLASGCPWMCSGRGICDAGRCVCDRG GGP YCVPVVPL & 1800 \\
\hline PSILKDDFNGNLHPDLWPEYYGAERGNLNGETTKSGTSLIFKGEGLPRLI & 1850 \\
\hline SRDLDCTNTMVQFSLRFIAKSTPERSHSILIQFSISSGGITWHLMDEFYF & 1900 \\
\hline 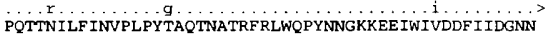 & 1950 \\
\hline WWNPVMLLDTFDFGPREDNWFFYPGGNIGL YCPYSSKGAPEEDSAMVFVS & 2000 \\
\hline VGCSTDSSSADPVRLEFSRDFGAT & 2050 \\
\hline
\end{tabular}

WHLLLPLYHSSSHVSSLCSTEHHPSSTYYAGTMQGWRREVVHFGKLHLC 2100 GSVRFRWYQGYYPAGSQPVTWAIDNVY IOPQCEmMCHQQGSCIMOTKCIC 2150

DPQYSGPTCKISTKNDDFLDDFEGQLEDRFLLMSGKRSRKCGILSSG 2200 NNLFFNEDGLRMLMTRDLDLSHARFVQFMRLGCGKVVPDPSQPVLLQY 2250 SLNGGLSWSLLQELLFSNSSNGGRYALEIPLKARSGSTRLRWWQPSENG 2300 HFYSPWIDQILIGGNISGNTVEDDFTTLDSRKWLLHGGTKMPVCGST 2350 GDALVFIEKASTRYVUSTDVAVNEDSELOIDAASCSVTDSCYAIELEYS 2400 VDLGLSWHPLVRDCLPTNVECSRYHLQRILVSDTFNXWTRITLPLPPYTR 2450

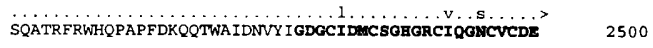
$\underset{\text { QWGGLYCDDPETSLPTQLKDNFNRAPSSONWLTWNGGKLSTVCGAVASGM }}{2550}$ ALHFSGGCSRLLVTVDLNINAEFTQFYYMYCLITPNNRNOGVLLEYSV 2600 NGGITWNLMEIFYDQYSKPGFVILLPPDAKEIATRFRWWQPHHDGLDQ 2650 NDWAIDNVIISGSADRTMLDTESSAPVPQHERSADAGPVGRTAEDMF 2700 MEDKTSWNEHWLFHDCTVERFCDSPGVMLCGSHDREVYAVTHDLTPT 2750 EGWIMQRKISVGCKVSEKIAQNQTHVYYSTDGUSWNYLVPQCLPADRKC 2800

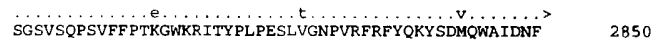

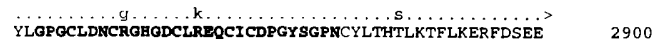
IKPDLWMSLEGGSTCTECGLLAEDTALYFGGSTVRQAVTQDLDLRGAKFL 2950

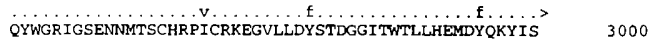
VRHDYILLPEDALTNTTRLRWWQPEVISNGIVVSGVERAQWALDNILIGG 3050

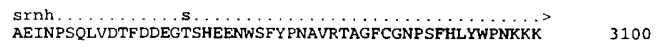
DKTHNALSSRELITQPGYMMQFKIVUGCEATSCGDLHSWMLEYTKDARSD 3150 SWQLVQTQCLPSSSNSTGCSPFEFHEATIYNSVNSSSWKRTTIQLPDHVS 3200

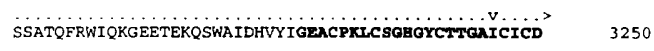
ESFQGDDSUFSHDLPSYTKDNFESARVTEANWETIQGGVIGSGCGQLAP 3300 YAHGDSYYFNGCQIRQAATKPLDLTRASKTMFULQTGSMSQTDSCNSDLS 3350 GPHADKAVLLY SVWNGITWHVIAQHQPKDFTQARRVSYNYPLEARMKG 3400

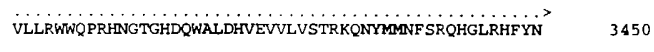
$\underset{\text { RRRRSLRRYP }}{\ldots \text { and }}$ 3461

Figure 3 Predicted amino acid sequence of human reelin. Based on the CDNA sequence (GenBank accession no. U79716), the amino acid sequence of human reelin was deduced and aligned against the mouse protein (GenBank accession no. U24703; D'Arcangelo et al. 1995), as indicated on the bottom and top lines, respectively. Residues conserved between the two species are shown as a dot in the mouse sequence. The conserved EGF-like domains are shown in bold, and the signal peptide is underlined. The valine residue depicted above a vertical bar (near the beginning) is an insertion in the mouse sequence.

\section{$160 \diamond$ GENOME RESEARCH}


HUMAN REELIN GENE

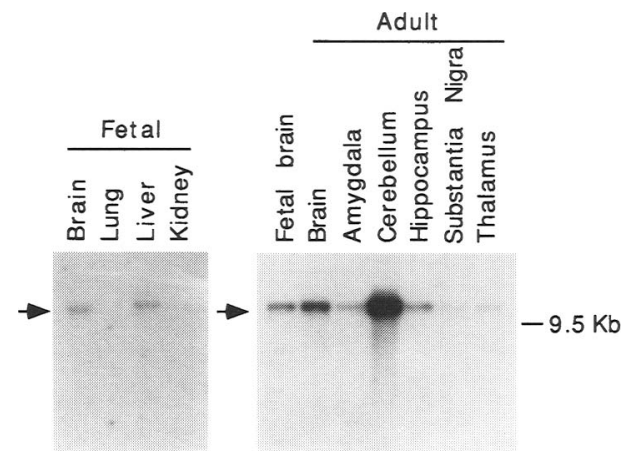

Figure $4 R E L N$ expression pattern. Membranes containing poly(A) RNA purified from multiple fetal tissues (left) or various brain regions (right) were hybridized with a radiolabeled $R E L N$-specific probe. A single hybridizing band of $\sim 12 \mathrm{~kb}$ (arrow) was seen in some RNA samples. An actin-specific probe was hybridized to the same membranes, and relatively equal hybridization signals were seen for all samples except for cerebellum RNA, which showed a slightly weaker signal (data not shown).

taken the first step toward investigating the structure and function of the human homolog of the gene responsible for the mouse neurodevelopmental mutation known as reeler.

The isolation of an overlapping set of cDNA clones allowed us to establish the nucleotide sequence of RELN. The human and mouse reelin proteins are both large and exhibit $94.2 \%$ identity at the amino acid level. The amino terminus of the human reelin protein consists of a signal peptide followed by a consensus cleavage site. The presence of a signal peptide with the lack of any other apparent transmembrane domain strongly suggests that human reelin is a secreted protein. The amino terminus also displays $28 \%$ amino acid identity to Fspondin, a protein secreted by the floor plate of the spinal cord that is thought to be involved in regulating adhesion and extension of axons in the developing central nervous system (Klar et al. 1992). Human reelin, like mouse reelin, has eight consecutive repeat sequences comprised of two related subdomains separated by an EGF-like motif. The latter is often associated with receptor-ligand interactions (Reichardt and Tomaselli 1991). The EGF-like motifs in reelin have the highest similarity with the extracellular matrix proteins tenascin, restrictin, and the integrin $\beta$-chain family (Reichardt and Tomaselli 1991). The RELN transcript is expressed in brain and liver, both at fetal and adult ages. In the adult brain, RELN mRNA levels are particularly elevated in the cerebellum. High levels of Reln mRNA in adult liver were not observed in the mouse (D'Arcangelo et al. 1995).

Currently, no human disease has been associated with RELN. One possibility is that RELN mutations are lethal in human embryos. Nevertheless, neuronal migration abnormalities have been observed in a number of human diseases. In one case, Kallmann syndrome, the disease affects migration of neurons secreting the hormone GnRH in the hypothalamus, resulting in hypogonadism and anosmia (Kallman et al. 1944; Rugarli and Ballabio 1993). The gene responsible for the $X$-linked form of Kallmann syndrome (KAL) has been identified and shown to code for a protein that shares sequence similarities with several neuronal cell adhesion molecules (Franco et al. 1991; Legouis et al. 1991). Interestingly, an autosomal form of Kallmann syndrome has been reported that involves a translocation involving 7q22 (Best et al. 1990), which is the general cytogenetic location of RELN. The possible association of $R E L N$ with this form of Kallmann syndrome is currently being investigated. The reagents and information reported here, particularly the cDNA sequence, the genomic and cDNA clones, and the availability of tightly linked genetic markers, should greatly enhance the study of RELN. Undoubtedly, this protein serves an important function in mammalian brain development, and it may be associated with human brain malformations.

\section{METHODS}

\section{Southern Hybridization Analysis}

Genomic DNA from various vertebrate species was obtained commercially (Clontech). The DNA (10 $\mu \mathrm{g}$ per lane) was digested with EcoRI, separated in a $0.8 \%$ agarose gel, and transferred to a Hybond nylon membrane (Amersham). The membrane was then hybridized with a mouse Reln probe corresponding to nucleotides 3268-3613, which was radiolabeled with $\left[\alpha-{ }^{32}\right.$ P]dCTP using an oligolabeling kit (Pharmacia). Following hybridization at $37^{\circ} \mathrm{C}$ in a standard buffer containing $50 \%$ formamide, the membrane was washed twice in $2 \times \mathrm{SSC} /$ $0.2 \% \mathrm{SDS}$ at $37^{\circ} \mathrm{C}$ and exposed to Kodak X-OMAT film.

\section{Isolation of cDNA Clones}

Based on the cDNA sequence of Reln (D'Arcangelo et al. 1995), a series of PCR assays were developed that amplified the appropriately sized products from human genomic DNA. In some cases, low-stringency PCR conditions (e.g., low annealing temperature) were required to achieve robust amplification from human DNA. The resulting PCR products were cloned into pCRII (Invitrogen) and sequenced using dyelabeled primers on an Applied Biosystems 373A sequencer.

The resulting human DNA sequence was used to design $R E L N$-specific oligonucleotides, which in turn were used to 


\section{DeSILVA EI AL.}

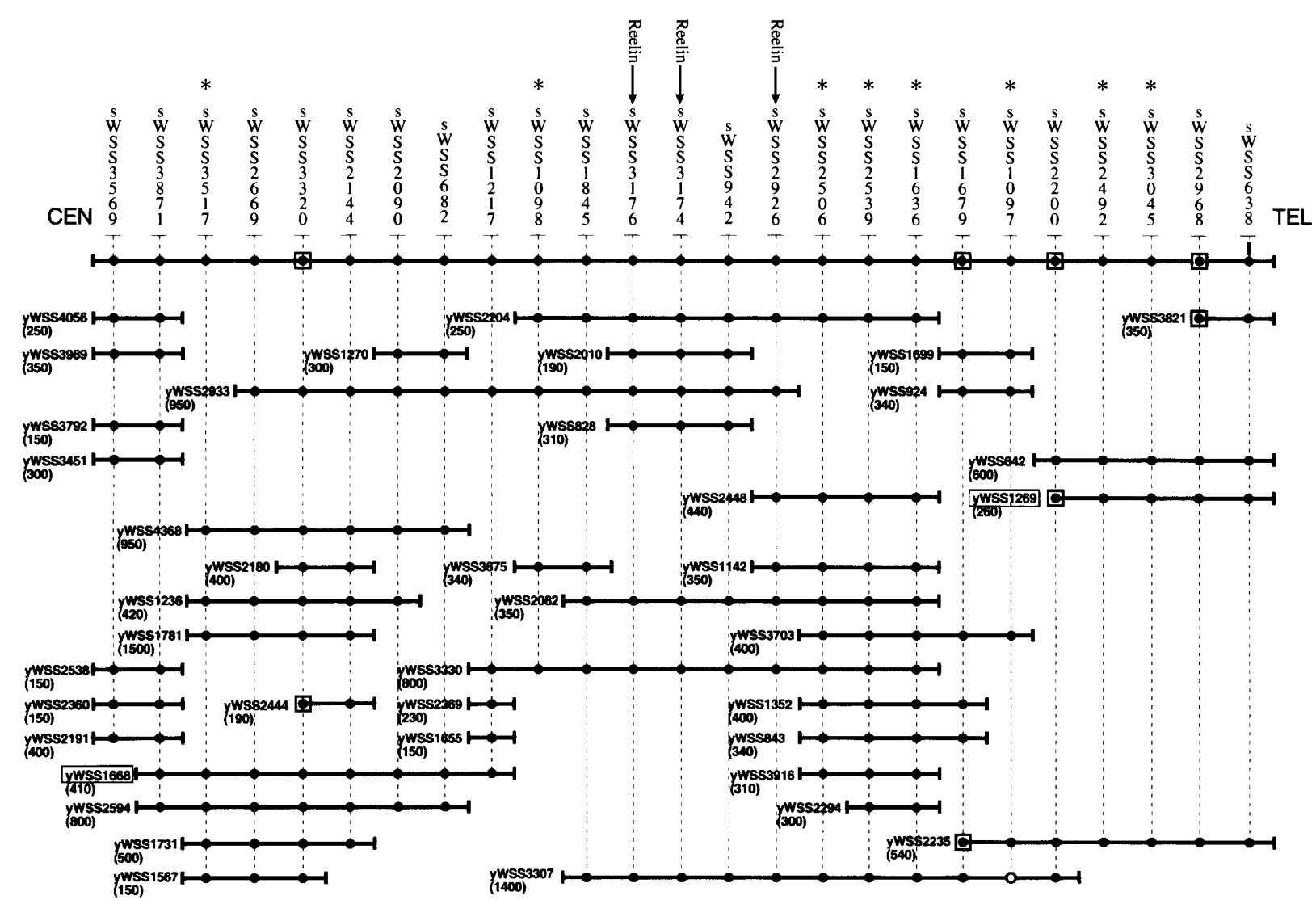

Figure 5 Localization of RELN on the YAC-based physical map. Three RELN-specific STSs were developed and mapped to a large YAC contig from human chromosome 7q22. A portion of this YAC contig is shown. Relevant information about all of the STSs (listed along the top) is available in GenBank and the Genome Database (GDB). The eight STSs corresponding to genetic markers are indicated with an asterisk ( ${ }^{*}$; see Table 1 ). A partial set of the YACs from this region is shown, with each estimated YAC size (in $\mathrm{kb}$, measured by pulsed-field gel electrophoresis) provided in parenthesis. The presence of an STS in a YAC is indicated $(\bullet)$ at the appropriate position, with the absence of an STS expected to be present (O). When an STS corresponds to the insert end of a YAC, a square $(\square)$ is placed around the corresponding - [both along the top (near the STS name) and at the end of the YAC from which it was derived]. Additional information about the YACs is available in GDB. Boxes are placed around the names of the two YACs (yWSS1269 and yWSS1668) that were mapped to 7q22 by FISH analysis (Green et al. 1994; data not shown). The relative positions of the centromere (CEN) and the $7 q$ telomere (TEL) are indicated. Note that $R E L N$ is transcribed in the telomeric to centromeric direction.

isolate clones from a Superscript human brain cDNA library (Life Technologies) using the GeneTrapper cDNA positive selection system (Life Technologies). A total of seven cDNA clones (ranging in size from 2.2 to $4.8 \mathrm{~kb}$ ) were isolated (see Fig. 2). Sequences of the insert ends of each clone were established and aligned with the mouse sequence to establish the extent of continuity. When gaps in clone coverage were detected and subsequent GeneTrapper cDNA isolation attempts failed to yield a desired clone, hybridization-based screening of an alternate cDNA library was performed. Approximately $10^{6}$ clones from a human cerebellum " 5 '-Stretch" cDNA library (Clontech) were plated at a density of $\sim 5 \times 10^{5}$ plaques per $24 \times 24-\mathrm{cm}$ screening plate (Nunc). Phage plaques were transferred in duplicate to Nextran Plus nylon membranes (Schleicher \& Schuell) and then denatured in $1.5 \mathrm{M} \mathrm{NaCl} / 0.5$ $\mathrm{N} \mathrm{NaOH}$ for $5 \mathrm{~min}$, neutralized in $1.5 \mathrm{M} \mathrm{NaCl} / 0.5 \mathrm{M}$ Tris- $\mathrm{HCl}$ for $5 \mathrm{~min}$, briefly washed in $2 \times$ SSC, and dried. Appropriate probes derived from existing cDNA clones (see above) were radiolabeled and hybridized to the nylon membranes using standard conditions. Two positive plaques were picked and rescreened. Inserts from these two cDNA clones were amplified by PCR, cloned into pCRII, and used for sequencing.

\section{Sequencing of cDNA Clones}

A subset of the isolated cDNA clones, selected to provide twofold coverage of most of the RELN sequence (see Fig. 2), were used to construct a custom subclone library suitable for shotgun sequencing (SeqWright, Houston, TX). Following excision with MluI, the inserts of the cDNA clones were mixed together, ligated end-to-end, and sheared with a nebulizer. The DNA fragments were end-repaired and subcloned into M13mp19 (Andersson et al. 1996). Random subclones were 


\section{Table 1. Microsatellite Markers Mapping Near RELN}

\begin{tabular}{|c|c|c|c|}
\hline \multirow[b]{2}{*}{ Name } & \multirow[b]{2}{*}{ Genetic marker name } & \multicolumn{2}{|c|}{ Accession no. } \\
\hline & & GDB & GenBank \\
\hline sWSS3517 & UT997 & GDB:312942 & L39153, L39154 \\
\hline sWSS1098 & AGM273vg5 & GDB:612027 & Z51237 \\
\hline sWSS2506 & AFMb348zb5 & GDB:661540 & Z53797 \\
\hline sWSS2539 & GATA6G06 & GDB:228764 & G09119 \\
\hline sWSS1636 & GATA4E02 & GDB: 686670 & G08623 \\
\hline sWSS1097 & AFM269zg1 & GDB:199652 & Z23925 \\
\hline sWSS2493 & AFMa275yc1 & GDB:608169 & Z52739 \\
\hline sWSS3045 & AFMb320ve1 & GDB:610899 & Z53567 \\
\hline \multicolumn{4}{|c|}{$\begin{array}{l}\text { The eight genetic markers mapping in close physical proximity to RELN (see Fig. 5) are listed. The sWSS name } \\
\text { corresponds to the STS used to localize the corresponding marker on the YAC-based physical map. The } \\
\text { genetic marker name reflects the microsatellite marker used for genetic mapping (with the appropriate GDB } \\
\text { and GenBank numbers indicated). Note that the actual PCR assays used for YAC-based physical mapping are } \\
\text { usually different from those used for genetic mapping, as the former typically employ primers that do not flank } \\
\text { the polymorphic tracts (Green et al. 1994). }\end{array}$} \\
\hline
\end{tabular}

sequenced to provide roughly sixfold coverage using fluorescent dye-labeled -21M13 universal primer (Applied Biosystems) and an Applied Biosystems 373A sequencer. Sequence assembly was performed with DNASTAR sequence analysis software. Gaps and ambiguities were resolved by targeted sequencing of selected subclones with custom primers and fluorescent dye-labeled terminators (Applied Biosystems). All bases were read on both strands to confirm the final sequence. Subsequent assembly and analysis of the DNA sequence was performed with either the DNASTAR or MacVector (Kodak) sequence analysis software.

\section{Northern Hybridization Analysis}

For analyzing $R E L N$ expression in fetal tissues, a 180-bp fragment corresponding to nucleotides 1114-1294 of the RELN cDNA was amplified by PCR (5'-CTCTACCTTCCTGAGGACGCCAA-3', 5'-AAGCCAGTTGCCTGTGTCCACTG-3'), gel purified, radiolabeled, and hybridized to a fetal tissue RNA blot (Clontech) in ExpressHyb (Clontech) as recommended by the manufacturer. For analyzing RELN expression in adult brain, poly(A) RNA from different brain regions (Clontech) was electrophoresed through a $1 \%$ agarose/formaldehyde gel ( $2 \mu \mathrm{g}$ per lane) and transferred to a Hybond nylon membrane (Amersham). The same probe as above was hybridized to these mRNAs in standard buffer containing 50\% formamide at $42^{\circ} \mathrm{C}$. The membrane was washed twice in $2 \times \mathrm{SSC} / 0.2 \%$ SDS, then once in $0.1 \times \mathrm{SSC} / 0.1 \% \mathrm{SDS}$ at $50^{\circ} \mathrm{C}$ and exposed to Kodak X-OMAT film.

\section{Mapping RELN on the YAC-Based Physical Map}

Three RELN-specific PCR assays (sWSS2926, sWSS3174, and sWSS3176; GenBank accession nos. G30936, G30937, G30938, respectively) were developed and optimized essentially as described (Green et al. 1991; Green 1993). These PCR assays were in turn used to screen the chromosome 7 YAC resource (Green et al. 1995).

\section{ACKNOWLEDGMENTS}

We thank Drs. Dennis Drayna, Gerry Bouffard, and Jeff Touchman for critical review of the manuscript and Gerry Bouffard for bioinformatics support. This work was supported in part by National Institutes of Health Cancer Center Support CORE grant P30-CA21765 (to T.C.), the American Lebanese Syrian Associated Charities (ALSAC), and National Research Service Award grant NS09698 from the National Institute of Neurological Disease and Stroke (to G.D.).

The publication costs of this article were defrayed in part by payment of page charges. This article must therefore be hereby marked "advertisement" in accordance with 18 USC section 1734 solely to indicate this fact.

\section{REFERENCES}

Andersson, B., M.A. Wentland, J.Y. Ricafrente, W. Liu, and R.A. Gibbs. 1996. A "double adaptor" method for improved shotgun library construction. Anal. Biochem. 236: 107-113.

Bar, I., M.C. Beckers, C. Dernoncourt, and A.M. Goffinet. 1994. The mouse neurological mutation Reeler maps in a region of proximal mouse chromosome 5 which is cosyntenic with human chromosome 7. Cytogenet. Cell Genet. 65: 73.

Best, L.G., W.A. Wasdahl, L.M. Larson, and J. Sturlaugson. 1990. Chromosome abnormality in Kallmann syndrome. Am. J. Med. Genet. 35: 306-309.

Caviness, V.S., Jr. and P. Rakic. 1978. Mechanisms of 


\section{DeSILVA ET AL.}

cortical development: A view from mutations in mice. Annu. Rev. Neurosci. 1: 297-326.

D'Arcangelo, G., G.G. Miao, S.-C. Chen, H.D. Soares, J.I. Morgan, and T. Curran. 1995. A protein related to extracellular matrix proteins deleted in the mouse mutant reeler. Nature 374: 719-723.

D'Arcangelo, G., K. Nakajima, T. Miyata, M. Ogawa, K. Mikoshiba, and T. Curran. 1997. Reelin is a secreted glycoprotein recognized by the CR-50 monoclonal antibody. J. Neurosci. 17: 23-31.

DeBry, R.W. and M.F. Seldin. 1996. Human/mouse homology relationships. Genomics 33: 337-351.

Franco, B., S. Guioli, A. Pragliola, B. Incerti, B. Bardoni, R. Tonlorenzi, R. Carrozzo, E. Maestrini, M. Pieretti, P. Taillon-Miller, C.J. Brown, H.F. Willard, C. Lawrence, M.G. Persico, G. Camerino, and A. Ballabio. 1991. A gene deleted in Kallmann's syndrome shares homology with neural cell adhesion and axonal path-finding molecules. Nature 353: $529-536$.

Goffinet, A.M. 1984. Events governing organization of post migratory neurons: Studies on brain development in normal and reeler mice. Brain Res. 319: 261-296.

1990. Determinants of nerve cell patterns during development: A review. Eur. J. Morphol. 28: 149-168.

1992. The reeler gene: A clue to brain development and evolution. Int. J. Dev. Biol. 36: 101-107.

Green, E.D. 1993. Physical mapping of human chromosomes: Generation of chromosome-specific sequence-tagged sites. In Methods in molecular genetics (Vol. 1): Gene and chromosome analysis (Part A) (ed. K.W. Adolph), pp. 192-210. Academic Press, San Diego, CA.

Green, E.D., R.M. Mohr, J.R. Idol, M. Jones, J.M. Buckingham, L.L. Deaven, R.K. Moyzis, and M.V. Olson. 1991. Systematic generation of sequence-tagged sites for physical mapping of human chromosomes: Application to the mapping of human chromosome 7 using yeast artificial chromosomes. Genomics 11: 548-564.

Green, E.D., J.R. Idol, R.M. Mohr-Tidwell, V.V. Braden, D.C. Peluso, R.S. Fulton, H.F. Massa, C.L. Magness, A.M. Wilson, J. Kimura, J. Weissenbach, and B.J. Trask. 1994. Integration of physical, genetic and cytogenetic maps of human chromosome 7: Isolation and analysis of yeast artificial chromosome clones for 117 mapped genetic markers. Hum. Mol. Genet. 3: 489-501.

Green, E.D., V.V. Braden, R.S. Fulton, R. Lim, M.S. Ueltzen, D.C. Peluso, R.M. Mohr-Tidwell, J.R. Idol, L.M. Smith, I. Chumakov, D.L. Paslier, D. Cohen, T. Featherstone, and P. Green. 1995. A human chromosome 7 yeast artificial chromosome (YAC) resource: Construction, characterization, and screening. Genomics 25: 170-183.

Kallman, F., W.A. Schoenfeld, and S.E. Barrera. 1944. The genetic aspects of primary eunuchoidism. Am. J. Ment. Defic. 48: $203-236$.

Klar, A., M. Baldassare, and T.M. Jessell. 1992. F-Spondin: A gene expressed at high levels in the floor plate encodes a secreted protein that promotes neural cell adhesion and neurite extension. Cell 69: 95-110.

Kozak, M. 1991. An analysis of vertebrate mRNA sequences: Intimations of translational control. J. Cell Biol.

115: 887-903.

Legouis, R., J.-P. Hardelin, J. Levilliers, J.-M. Claverie, S. Compain, V. Wunderle, P. Millasseau, D. Le Paslier, D. Cohen, D. Caterina, L. Bougueleret, H. Delemarre-Van de Waal, G. Lutfalla, J. Weissenbach, and C. Petit. 1991. The candidate gene for the X-linked Kallmann syndrome encodes a protein related to adhesion molecules. Cell 67: 423-435.

O'Brien, S.J., J.E. Womack, L.A. Lyons, K.J. Moore, N.A. Jenkins, and N.G. Copeland. 1993. Anchored reference loci for comparative genome mapping in mammals. Nature Genet. 3: 103-112.

Ogawa, M., T. Miyata, K. Nakajima, K. Yagyu, M. Seike, K. Ikenaka, H. Yamamoto, and K. Mikoshiba. 1995. The reeler gene-associated antigen on Cajal-Retzius neurons is a crucial molecule for laminar organization of cortical neurons. Neuron 14: 899-912.

Reichardt, L.F. and K.J. Tomaselli. 1991. Extracellular matrix molecules and their receptors: Functions in neural development. Annu. Rev. Neurosci. 14: 531-570.

Rugarli, E.I. and A. Ballabio. 1993. Kallmann syndrome: From genetics to neurobiology. J. Am. Med. Assoc. 270: 2713-2716.

Takahara, T., T. Ohsumi, J. Kuromitsu, K. Shibata, N. Sasaki, Y. Okazaki, H. Shibata, S. Sato, A. Yoshiki, M. Kusakabe, M. Muramatsu, M. Ueki, K. Okuda, and Y. Hayashizaki. 1996. Dysfunction of the Orleans reeler gene arising from exon skipping due to transposition of a full-length copy of an active L1 sequence into the skipped exon. Hum. Mol. Genet. 5: 989-993.

von Heijne, G. 1983. Patterns of amino acids near signal-sequence cleavage sites. Eur. J. Biochem. 133: 17-21.

1986. A new method for predicting signal sequence cleavage sites. Nucleic Acids Res. 14: 4683-4690.

Received September 19, 1996; accepted in revised form December 17, 1996. 


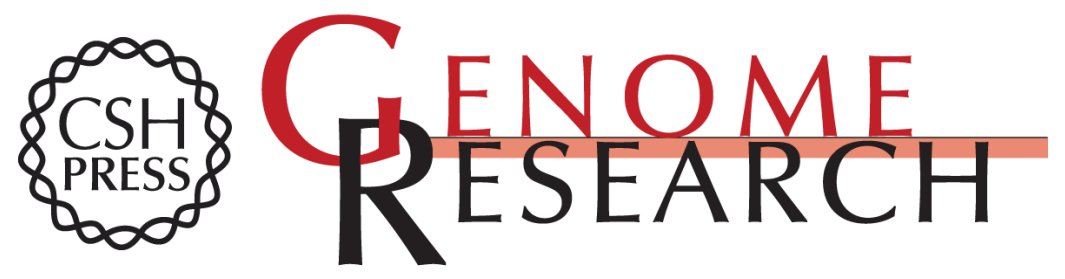

\section{The human reelin gene: isolation, sequencing, and mapping on chromosome 7.}

U DeSilva, G D'Arcangelo, V V Braden, et al.

Genome Res. 1997 7: 157-164

Access the most recent version at doi:10.1101/gr.7.2.157

References This article cites 25 articles, 2 of which can be accessed free at:

http://genome.cshlp.org/content/7/2/157.full.html\#ref-list-1

\section{License}

Email Alerting Receive free email alerts when new articles cite this article - sign up in the box at the Service top right corner of the article or click here.

\section{Affordable, Accurate Sequencing.}

To subscribe to Genome Research go to: https://genome.cshlp.org/subscriptions 